Proceedings of the XXIII Conference on Applied Crystallography, Krynica Zdrój, Poland, September 20-24, 2015

\title{
Analysis of Texture and Microstructure of Annealed Fe-23Mn-3Si-3Al Steel
}

\author{
J. KOWALSKA* \\ AGH University of Science and Technology, Faculty of Metals Engineering and Industrial Computer Science, \\ Cracow, Poland
}

\begin{abstract}
Texture and microstructural examinations of $\mathrm{Fe}-23 \% \mathrm{Mn}-3 \% \mathrm{Si}-3 \% \mathrm{Al}$ (mass\%) alloy are presented. After casting the ingot was homogenized at $1150^{\circ} \mathrm{C}$, hot-rolled in the temperature range $1200{ }^{\circ} \mathrm{C}-900^{\circ} \mathrm{C}$ and then coldrolled. Steel samples, after $40 \%$ deformation, were annealed at $300^{\circ} \mathrm{C}$ for $10 \mathrm{~min}, 600^{\circ} \mathrm{C}$ and $750^{\circ} \mathrm{C}$ for 30 min. $\mathrm{X}$-ray diffraction and metallographic studies revealed deformation-induced mechanical twinning and phase transformation. The crystallographic Shoji-Nishiyama and Kurdjumov-Sachs relations between martensite $\left(\varepsilon, \alpha^{\prime}\right)$ and austenite $(\gamma)$, were found in the cold-rolled material. During annealing the reverse martensite to austenite transformation occurred.
\end{abstract}

DOI: 10.12693/APhysPolA.130.946

PACS/topics: 81.40.Ef, 81.40.-z, 61.05.cp, 61.50.Ks, 68.37.Lp

\section{Introduction}

In the recent decades, a substantial interest has been attracted by high-manganese steels. They possess very good functional properties as far as combination of strength and plasticity is concerned [1]. In these alloys, plastic deformation may take place by twinning (the TWIP effect - twinning induced plasticity) or a martensitic transformation induced by deformation (the TRIP effect - transformation induced plasticity) [1-6]. In numerous cases both of those effects may occur simultaneously. That, in turn, is dependent upon the chemical composition and the temperature of deformation. It had been presumed that if the content of a manganese in a steel does not reach 15 mass percent, it manifests the TRIP effect, and between 15 a $25 \%$, TRIP and TWIP effects are observed. In turn, when the quantity of manganese in a steel is higher than $25 \%$, then the dominant mechanism of deformation is twinning [4]. Temperature exerts a substantial influence upon stacking fault energy, and, as a result, the stability of austenite. Simultaneously with decrease in temperature, decrease in the value of stacking-fault energy is observed, which is conducive to martensitic transformation [7].

There is a close correlation between factors determining the formation and the development of deformation texture and stacking-fault energy. The development of the texture in the course of deformation and annealing is very important because it determines mechanical properties, which, in turn, define the suitability of a steel for industrial applications.

In this paper, the subject matter of the analysis is the results of the research conducted into the $\mathrm{Fe}-23 \mathrm{Mn}-3 \mathrm{Si}-$ $3 \mathrm{Al}$ high-manganese steel, in which in the course of cold

\footnotetext{
* corresponding author; e-mail: joannak@agh.edu.pl
}

plastic deformation, there occurs both martensitic transformation induced by deformation, and also mechanical twinning alike. In turn, in the course of annealing the deformed steel, there occurred the reverse transformation of martensite into austenite.

\section{Material and methods}

The $22.96 \%$ manganese, $2.85 \%$ silicon, $2.66 \%$ aluminium and $0.065 \%$ carbon steel was cast in a vacuum induction furnace. After casting, the ingot was subjected to homogenization at $1150^{\circ} \mathrm{C}$ and hot rolling from the starting temperature of $1200^{\circ} \mathrm{C}$. The material was then subjected to cold deformation by laboratory rolling to $40 \%$. The steel was subsequently annealed at $300^{\circ} \mathrm{C}$ for $10 \mathrm{~min}$, at $600^{\circ} \mathrm{C}$ for $30 \mathrm{~min}, 750^{\circ} \mathrm{C}$ for $30 \mathrm{~min}$, and cooled in air.

Samples for the diffraction research were ground on abrasive papers, polished by diamond pastes and, subsequently, electrically polished. For the purpose of the X-ray examinations, the following diffractometers: Bruker D8 Advance, Siemens D500 and D5000 were used (Co $K_{\alpha}, \mathrm{Cu} K_{\alpha}$ and Mo $K_{\alpha}$ radiation, respectively). Diffraction research included qualitative phase analysis and the measurement of a crystallographic texture.

Samples for metallographic research were taken from the longitudinal section of a sheet. The observations of the microstructure were performed on a JEM 200CX transmission electron microscope.

\section{Results and discussion}

The diffractogram presented in Fig. 1 for the initial state of the $\mathrm{Fe}-23 \mathrm{Mn}-3 \mathrm{Si}-3 \mathrm{Al}$ alloy shows that the steel possesses a single-phase austenitic $(\gamma)$ structure. On the diffractogram of the samples after $20 \%$ deformation (Fig. 1), apart from peaks, originating from austenite $(\gamma)$, there appear additional diffraction lines from martensite 
$\varepsilon$ and $\alpha^{\prime}\left((101) \varepsilon,(103) \varepsilon,(110) \alpha^{\prime},(200) \alpha^{\prime}\right.$ and $\left.(211) \alpha^{\prime}\right)$. Simultaneously with increase in deformation, reaching $40 \%$, further changes in the diffraction image are observed. The peaks originating from martensite $\varepsilon$ are not present, whereas there increases the intensity of the lines originating from martensite $\alpha^{\prime}$ (Fig. 1). This indicates that martensitic transformation induced by deformation occurs in the following manner: $\gamma \rightarrow \varepsilon$ and $\varepsilon \rightarrow \alpha^{\prime}$. It was not possible to detect by X-ray methods the remaining amount of martensite $\varepsilon$ at this stage of deformation. In the diffraction image pattern of the sample after annealing at $300^{\circ} \mathrm{C}$, the intensity of peaks originating from the phases: $\gamma$ and $\alpha^{\prime}$ increases, which is caused by recovery processes. Simultaneously with increase in the temperature of annealing, it is possible to observe the decrease in the intensity of peaks originating from martensite $\alpha^{\prime}$. After annealing at $750^{\circ} \mathrm{C}$, only the lines originating from a single phase of austenite $\gamma$ are present on the diffractogram (Fig. 1). This is evidence that a reverse transformation $\alpha^{\prime} \rightarrow \gamma$ has occurred. Data in the literature [8] state that reverse transformation $\varepsilon \rightarrow \gamma$ occurs at temperatures of $100^{\circ} \mathrm{C}-250{ }^{\circ} \mathrm{C}$, whereas the transformation $\alpha^{\prime} \rightarrow \gamma$ is in the temperature range $500{ }^{\circ} \mathrm{C}-700^{\circ} \mathrm{C}$.
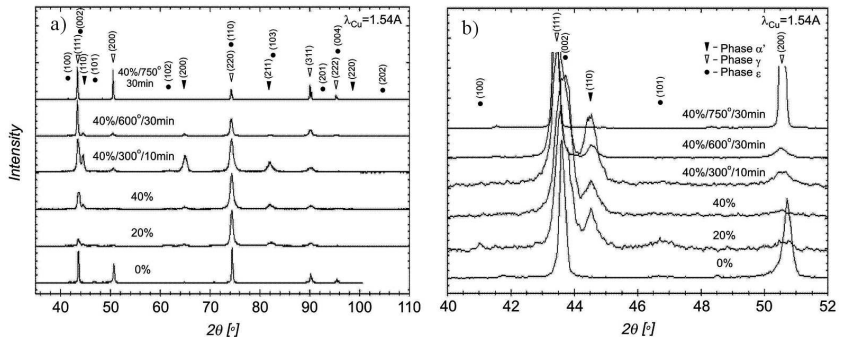

Fig. 1. X-ray diffractions patterns of the Fe-23Mn-3Si$3 \mathrm{Al}$ alloy, (a) in the initial state $(0 \%)$, after $20 \%$ and $40 \%$ cold-rolling, and after annealing at $300{ }^{\circ} \mathrm{C}, 600^{\circ} \mathrm{C}$ and $750^{\circ} \mathrm{C}$, (b) the expanded plot of the (111) and (200) for austenite and the (002) and (101) for martensite $\varepsilon$ peaks (b).

The analysis of a crystallographic texture was conducted upon the basis of orientation distribution function (ODF)ODF and the selected full pole figures (Figs. 2-4).

Austenite in the initial sample possesses a comparatively strong texture, and the maximum was compatible with the Goss orientation $\{110\}\langle 001\rangle$. The main texture components of austenite are related to the fibre $\alpha=\langle 110\rangle \| \mathrm{ND}$ (normal direction) (Fig. 2a). The texture indexes of austenite increase after $20 \%$ of deformation. The maximum value of ODF $f(g)=15.1$ is compatible with the Goss orientation. In the texture (Fig. 2b), a weak orientation $\{113\}\langle 332\rangle$ was observable. After $40 \%$ deformation, the degree of the texturization of austenite decreases, which is connected with the phase transformation $\gamma \rightarrow \varepsilon \rightarrow \alpha^{\prime}$ (Fig. 2c). The disappearance of the component $\{112\}\langle 111\rangle$ was observed. This is evidence for the occurrence of mechanical twinning. This lack of that orientation may be connected with, that in

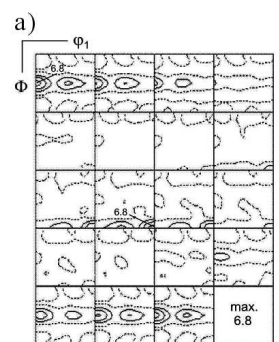

d)
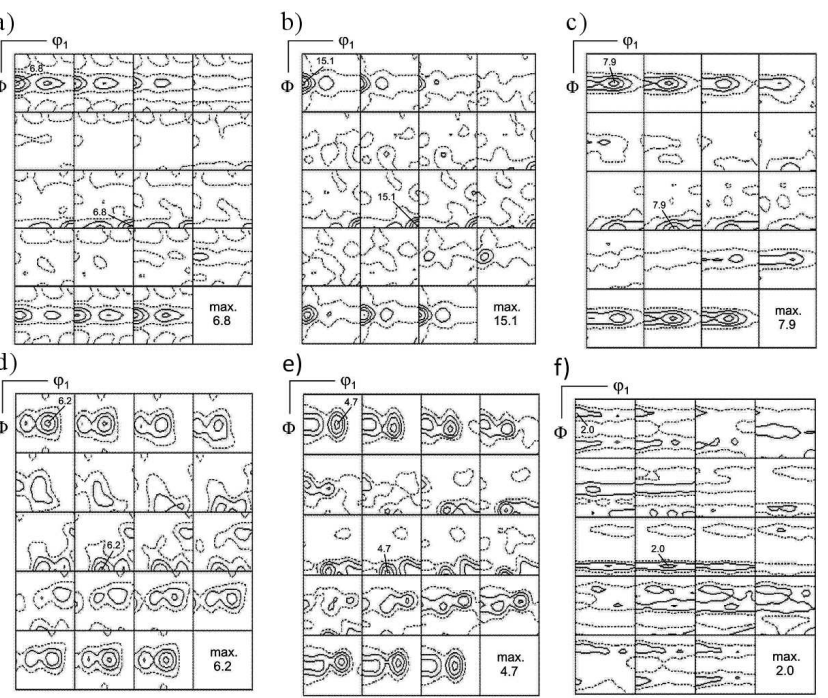

Fig. 2. Orientation distribution functions in sections $\phi_{2}$ const for austenite (a) in the initial state, (b) after $20 \%$ cold-rolling, (c) after $40 \%$ cold-rolling, (d-f) after $40 \%$ cold-rolling and annealing at $300^{\circ} \mathrm{C}, 600^{\circ} \mathrm{C}$ and $750{ }^{\circ} \mathrm{C}$, respectively.
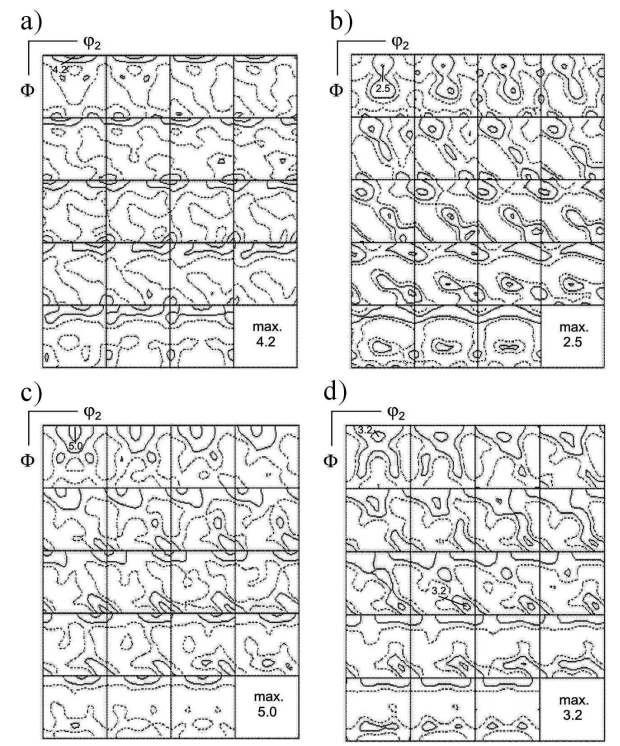

Fig. 3. Orientation distribution functions in sections $\varphi_{1}=$ const for martensite $\alpha^{\prime}$ after (a) $20 \%$ cold-rolling, (b) $40 \%$ cold-rolling, (c, d) $40 \%$ cold-rolling and annealing at $300{ }^{\circ} \mathrm{C}$ and $600{ }^{\circ} \mathrm{C}$, respectively.
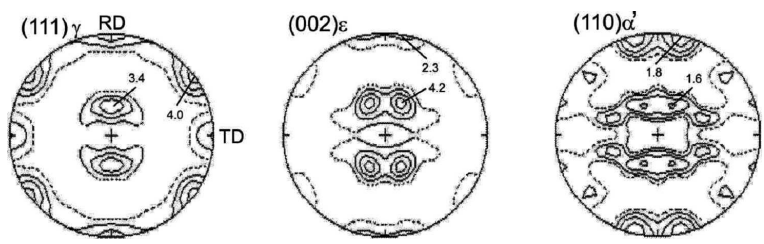

Fig. 4. Calculated pole figure for austenite (111) $\gamma$, for hexagonal martensite $(002) \varepsilon$ and for regular martensite (110) $\alpha$ '- sample after $20 \%$ cold-rolling. (RD - rolling direction, TD - trasnsverse direction). 
accordance with the Kurdjumov-Sachs relationship, it is becoming to the orientation $\{112\}\langle 110\rangle$ of martensite [9]. The maximum of ODF is compatible with the orientation $\{110\}\langle 557\rangle$ (Fig. 2c). The texture of austenite after deformation tends to become a texture of alloy type. This is a typical orientation in the metals and alloys which have a regular structure with low level of stacking-fault energy.

After annealing at $300^{\circ} \mathrm{C}$, the texture of austenite is relatively weak. The $\alpha=\langle 110\rangle \|$ ND fibre undergoes shortening, and stretched from the orientation $\{110\}\langle 001\rangle$ to $\{110\}\langle 447\rangle$. In the texture, it is still possible to observe a weak component $\{113\}\langle 332\rangle$, and there occurs the $\mathrm{S}$ type orientation $\{123\}\langle 364\rangle$ (Fig. 2d). Annealing at $600{ }^{\circ} \mathrm{C}$ causes changes in the texture, and the degree of texturization decreases. Weakening is observed in the orientation $\{110\}\langle 112\rangle$ and the component $\{113\}\langle 332\rangle$ disappears (Fig. 2e).

Annealing at $750{ }^{\circ} \mathrm{C}$ results in clear weakening of the texture. Orientations in the $\alpha=\langle 110\rangle \| \mathrm{ND}$ fibre disappear. It is possible to observe two restricted weak fibres $\{013\}\langle u v w\rangle$, having the strongest orientation $\{013\}\langle 100\rangle$. That is connected with the occurring of recrystallization processes (Fig. 2f). Even though a typical component occurring in the texture of recrystallized austenite is a cubic orientation $\{100\}\langle 001\rangle$, regardless of that, in the case of this steel, that orientation is absent. Similar results were reported in the paper of Escobar and collaborators [8].

The texture of martensite $\alpha^{\prime}$ after deformation is comparatively weak. The maximum value of ODF is within the fibre $\alpha_{1}=\langle 110\rangle \| \mathrm{RD}$ and is compatible with the orientation $\{100\}\langle 011\rangle-20 \%$ deformation and the component $\approx\{311\}\langle 011\rangle-40 \%$ deformation (Fig. 3a and b). In the material after $20 \%$ deformation, orientations found in the fibre: $\varepsilon=\langle 001\rangle \| \mathrm{ND}$ (Fig. 3a) became noticeable in the texture as well.

After annealing at $300^{\circ} \mathrm{C}$, the texture becomes more acute, which is connected with the recovery processes occurring (Fig. 3c). After annealing at $600^{\circ} \mathrm{C}$, the degree of texturization decreases. In this temperature range, there occurs a reverse transformation $\alpha^{\prime} \rightarrow \gamma$. Texture of martensite $\alpha^{\prime}$ becomes random, still manifesting a fibrous character. In the texture, there occur weak orientations found in the fibres $\alpha_{1}=\langle 110\rangle \| \mathrm{RD}$ and $\varepsilon=\langle 001\rangle \| \mathrm{ND}$ (Fig. 3d).

In Fig. 4, the pole figures (111) $\gamma,(002) \varepsilon$ and $(110) \alpha^{\prime}$ for samples after $20 \%$ deformation are presented. It was ascertained that there occur crystallographic correlations between austenite $(\gamma)$ and martensite $\left(\varepsilon\right.$ and $\left.\alpha^{\prime}\right)$. The relation between the phases $\gamma$ and $\varepsilon$ is referred to as the Shoji-Nishiyama relationship (S-N) $\{002\} \varepsilon \|\{111\} \gamma$ and $\langle 110\rangle \varepsilon \|\langle 110\rangle \gamma[10]$. Such a correlation was reported also in other papers devoted to high-manganese steels $[5,6,11]$.

The relation between certain orientations of austenite and martensite $\alpha^{\prime}$ is described by the Kurdjumov-Sachs relationship (K-S) $\{111\} \gamma \|\{101\} \alpha^{\prime}$ and $\langle 101\rangle \gamma \|\langle 111\rangle \alpha^{\prime}$. It is possible to observe that not all the variants are being conducted, and that the transformations: $\gamma \rightarrow \varepsilon$ and $\gamma \rightarrow \alpha^{\prime}$ occur with the variant selection (Fig. 4).

The microstructure of the steel after different degrees of plastic deformation was discussed in detail in Ref. [12] and this article only shows the microstructure after $40 \%$ deformation.

Then micro-deformation twins and martensite $\alpha^{\prime}$, are observable (Fig. 5a and b). After annealing at $300^{\circ} \mathrm{C}$, bands are observed in the microstructure and in these bands new crystallites of austenite are formed. a)

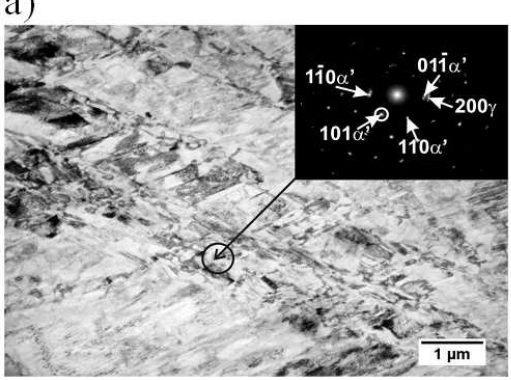

d)

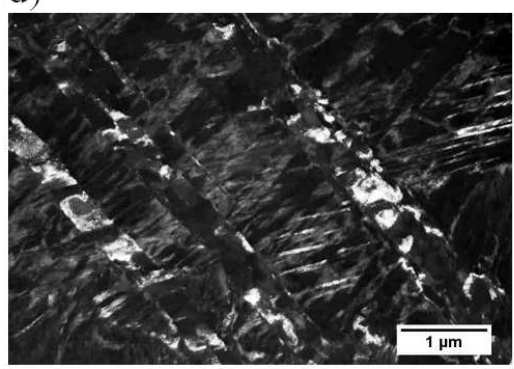

b)

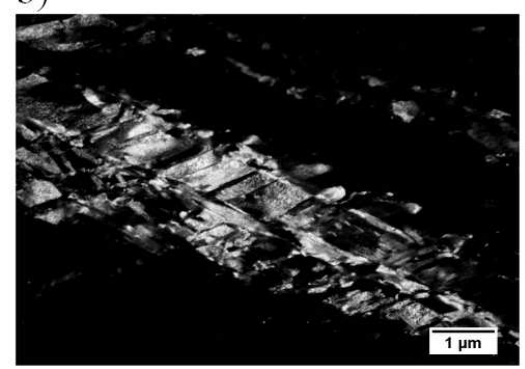

e)

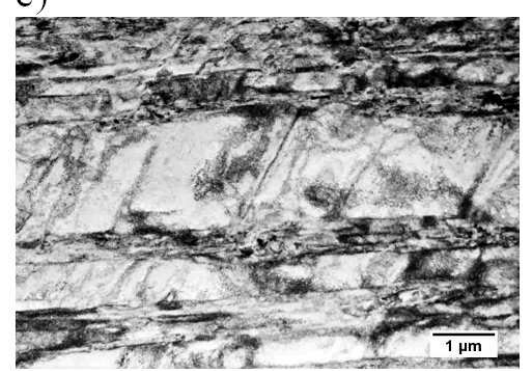

c)

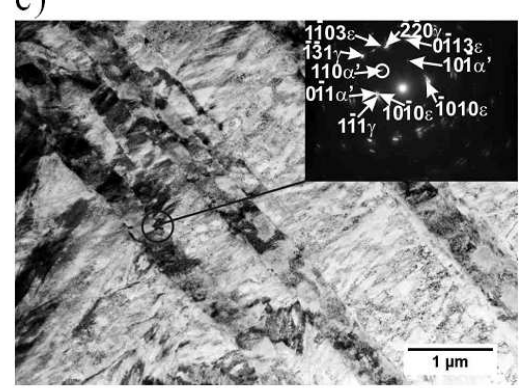

f)

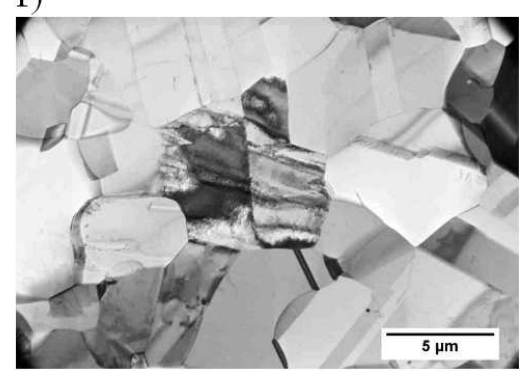

Fig. 5. TEM micrographs of Fe-23Mn-3Si-3Al alloy: (a-b) after $40 \%$ cold-rolling, bright field (BF) diffraction pattern $[\overline{1} 11] \alpha^{\prime}$ and dark field (DF) with $(101) \alpha^{\prime}$ after $40 \%$ cold-rolling and annealing: (c-d) $300^{\circ} \mathrm{C}$ for 10 minutes, $\mathrm{BF}$ diffraction pattern $[\overline{1} 12] \gamma\left\|[\overline{1} 11] \alpha^{\prime}\right\|[12 \overline{1} 1] \varepsilon$ and $\mathrm{DF}$ with $(110) \alpha^{\prime}$, (e) $600{ }^{\circ} \mathrm{C}$ for 30 minutes, $\mathrm{BF}$, (f) $750{ }^{\circ} \mathrm{C}$ for 30 minutes, BF. 
Data in the literature indicate that in this temperature range there occurs the following transformation: $\varepsilon \rightarrow \gamma[8]$. In the structure, apart from austenite, the martensite ( $\varepsilon$ and $\alpha^{\prime}$ ) are present, which is observable by selective diffraction. Dark field observation shows that martensite $\alpha^{\prime}$ it is situated principally in shear bands (Fig. 5c and d). In the sample annealed at $600{ }^{\circ} \mathrm{C}$, the band character of the microstructure is maintained (Fig. 5e). After annealing at $750^{\circ} \mathrm{C}$, recrystallization of austenite occurs, but regardless of that, there are very few observable areas which are not crystallized (Fig. 5f).

\section{Summary}

Analysis of the texture and the microstructure of the Fe-23Mn-3Si-3Al metastable steel is complex, because in the course of cold plastic deformation there simultaneously occur deformation of austenite, phase transformation induced by deformation: $\gamma \rightarrow \varepsilon \rightarrow \alpha^{\prime}$ and deformation of martensite formed at a given stage of plastic working. In the course of annealing this steel, the reverse transformation $\varepsilon \rightarrow \gamma$ and $\alpha^{\prime} \rightarrow \gamma$ occurred. After annealing the texture of austenite underwent weakening, which is connected with occurring recrystallization processes.

\section{Acknowledgments}

This work was sponsored by the Polish National Science Centre under contract No. 2011/01/D/ST8/03905. Appreciation is also expressed to Prof. A.S. Wronski (University of Bradford, UK), who edited the text.

\section{References}

[1] O. Grässel, G. Frommeyer, C. Derder, H. Hofmann, J. Phys. IV 110, 383 (1997).

[2] S. Alain, J.-P. Chateau, O. Bouaziz, S. Migot, N. Guelton, Mater. Sci. Eng. A 387-389, 158 (2004).

[3] Y.F. Shen, C.H. Qui, L. Wang, X. Sun, X.M. Zhao, L. Zuo, Mater. Sci. Eng. A 561, 329 (2013).

[4] H. Ding, H. Ding, D. Song, Z. Tang, P. Yang, Mater. Sci. Eng. A 528, 868 (2011).

[5] J. Kowalska, W. Ratuszek, M. Witkowska, A. Zielińska-Lipiec, T. Tokarski, J. Alloys Comp. 643, S39 (2015).

[6] J. Kowalska, W. Ratuszek, M. Witkowska, A. Zielińska-Lipiec, J. Alloys Comp. 615, S583 (2014).

[7] M. Koyama, T. Sawaguchi, T. Lee, C.S. Lee, K. Tsuzaki, Mater. Sci. Eng. A 528, 7310 (2011).

[8] D.P. Escobar, S.S. Ferreira de Dafé, D.B. Santos, J. Mater. Res. Technol. 4, 162 (2015).

[9] S.G. Chowdhury, S. Das, P.K. De, Acta Mater. 53, 3951 (2005).

[10] W. Zhang, Z. Liu, Z. Zhan, G. Wang, Mater. Lett. 91, 158 (2013).

[11] Y. Lü, B. Hutchinson, D.A. Molodov, G. Gottsrein, Acta Mater. 58, 3079 (2010).

[12] J. Kowalska, W. Ratuszek, M. Witkowska, A. Zielińska-Lipiec, M. Kowalska, Arch. Metall. Mater. 60, 1789 (2015). 